\title{
Social Media on Racism of African American in USA
}

\author{
Junhan Cai ${ }^{1, *}$
}

\author{
${ }^{1}$ FBMK, Universiti Putra Malaysia, SERDANG, MALAYSIA \\ *Email: 204731@student.upm.edu.my
}

\begin{abstract}
This article applies ethic identity theory to the existence of racial discrimination towards African American in social media platform. With theory applied, the article highlights the development of ethnic identity during structural suppression history and contemporary epoch of new media in the first place, and coalesces with social media in terms of investigation about: How the ethnic identity gets boosted? How ethnic boundaries originates? How the ethnicity manifests? What the societal attributes to the imbalance among different ethnic groups are? What viable solutions to imbalance are? As the culmination, there are two methods from the lens of a nation proposed in this article to terminate the racism against African American, which are the identifications both in ethnic group and nation. On the one hand, acknowledgement and deference for diversified culture of each ethnic group is the how muti-race nation should administrate the identification for ethnic group. On the other hand, while satisfying the fundamental needs is the prerequisite, mutual comprehensive development of each ethnic group in the direction of unitary politics and promotion of heterogeneous ethnic identity are the essential procedures to achieve the identification of nation.
\end{abstract}

\section{Keywords: Social media, Racism, African American, Ethnic group, Relative deprivation.}

\section{INTRODUCTION}

A student from FSU university, Mandy Thurston, uploaded a post through her social media account Vine, which was disseminated virally and exerted repercussion for black community [1]. In that post, she typed "welcome to FAMU... I mean FSU" together with hashtag \#monkeyseverywhere and attached a picture where a group of African American students was attending the university event. There are several critical signifiers involved unambiguously referring towards typical racism. Among these, the signifier, where the students in the photo were categorized on the basis of skin color and other physical signs and particularly for students from black community they were dehumanized as monkey, negates the racial identity of African American students while stereotyping the physical traits and abrasively muddling the species identity in a sense of persiflage.

Currently, mainstream social media plays a role of prevalent tools exercising democratic rights, meanwhile it is the hotbed where hate speech and racism thrive. Speaking of universal racial discrimination against African American in social media, it is undoubted that most of the racist mocking and stigmatizing the black community on the biological physical signs. "Racist speculates the human biological corporal signs as perpetual racial 'tattoo', which distorts or obliterates history and culture of other races, they acknowledge themselves as the representative of civilizational advancement and legitimate supervisor of underdeveloped race, referring to that, they are empowered with historic obligation to domesticate the evil and rescue the degenerate" [2]. According to racist, they arbitrarily correlate the biological traits with intelligence and degree of civilization. In other words, the student, who posted that racist content expressed her resentful sentiment due to the omnipresence of African American students while disseminating the racism, dedicated herself into recurrence of racial segregation history accomplishing so-called historic obligation.

The kernel of this article revolves around the conceptualization of ethnic identity probing into the emergence of racism in social media and proposing potential solutions to it. The article is initiated from the lens of history, observing aftermath and impacts of ethnic identity at the shadow of the systematic discrimination of African American history, and briefly discussing the evolution of ethnic identity in modern new media era; elaborating the boundaries between different ethnic groups which establishes the racism, and introducing essentialism and instrumentalism to 
illustrate the forms of ethnic expression together with their representations in social media; analyzing the specific causation of imbalanced perception between ethnic groups due to ethnic expression, while applying Relative Deprivation Theory to the anatomy of African American's psychological activity as underprivileged group as well as the hidden consequence; lastly the article introduces dual identity concept to undermine the inequality of ethnic groups and terminate the racial discrimination.

\section{HISTORICAL STAGES OF STRUCTURAL DISCRIMINATION}

Before further manifestation on discussion regarding black community being racially judged in social media, there is a prerequisite to propose ahead which is the suppressing and exploitative historical stage, and the evolution of black ethnic identity towards itself and other ethnic groups. Historically and chronologically, there are generally three stages: emancipation from slavery and acknowledgement of legal status, criminalization of black body and mass incarceration, tactical oppression of black activism by federal agency.

1866, an epochal year for African American. One year after the culmination of slavery, it was the year when the former Confederate legislatures enacted a set of laws known as The Black Code referring to the Thirteenth Amendment "extending the right to marry, enter contracts, and other basic legal entitlements, in most states newly freed people could not vote, own arms, or testify in court" [3]. Substantially, African American did not escape from imprisonment of slavery, instead they were continuously and legally exploited by slaveholder. Although later the Congress promulgated the fourteenth Amendment acknowledging the citizenhood of black American, due process, equal protection and related terms, United States as a country implementing federal system, southern states did not advocate the acknowledgement. During that period of time, black American residing in south was still held in captivity among plantation, coal mines, sawmills, and railroad camps, as documented in notorious Jim Crow South "the convict-lease and sharecropping systems did not fundamentally disrupt the racial hierarchies that had existed under slavery" [4].

As a prevalent perception at that time, black ethnic group represented criminal and criminality in the shadow of undeniable and objective data. Racism was cultivated and submerged in the major population of USA, which gave rise to the consequence where the public lynched the black community to gratify and sustain the so-called justice. "In effect, lynching became a means to police the activities of black people as well as their access to the economic sector, the way they chose to spend their leisure time, and their connection to the franchise and political sphere".
Unfortunately, criminalization of African American did not get thwarted or vanish whilst time elapsed, instead skyrocketing criminality rate and captivity rate lead to severer situation, racist ideology among other ethnic group was consistently reinforced verified by increasing scale of criminals. In late nineteenth century, under the fact that crime rate reached its climax repeatedly, historian Khalil Muhammad from the lens of the public and politicians depicted black group "as a uniquely dangerous and lawbreaking group and justified the perpetual expansion of the American prison system, sustained harsh sentencing practices, informed decisions surrounding capital punishment, and sanctioned racial profiling in general" [3]. Quoted from another historian in terms of judicial department that "operating as racial partisans rather than public servants in moments of interracial conflict" [5].

It was 1968 when the first mass incarceration demonstrated its emergence in historical stage, abominable relationship between law-enforcing department and black people deteriorated witnessed by the Omnibus Crime Control and Safe Streets Act of 1968. The introduction of this law "marked a critical turning point in the long history of the antiblack punitive tradition and the use of police forces to control, contain, and confine African Americans" [3]. In the meantime, federal government advocated the prison construction, especially when Street Safety terms was implemented, the scale was multiplied in geometric growth accompanying with sharp increasement in amount of black prisoner. National expansion of prison system manifested the new era of mass incarceration. Unexpectedly, the crime rate did not descend yearly, however, with increased judicial supervision towards African American engaged by local government, record of maximum criminal under incarceration broke yearly.

Obviously, mass incarceration was the direct consequence to War On Crime, meanwhile, including policing department local federal agencies advanced and upgraded their strategic deployment aiming at the criminality. From community-oriented surveillance cooperating with various authority departments, to the first time in utilization of Countersurveillance Program by FBI. Ironically, US president relieved successively over time, the motion of systematic and judicial black oppression perpetuates.

Throughout the chronicle of black struggles, the suppressing history essentially originated from systematic and prolonged exploitation by dominating group. For black ethnic group, every member inside should be entitled as warrior during the racial war, ethnic identity empowers them with persistence and bravery from slavery to mass incarceration. Suffering reinforces the ethnic identity among black community. As an underprivileged ethnic group, they demonstrated astonishing vitality against the inequality due to 
imbalanced social status and contempt from another ethnic group, while attempting to thrive attributing to the dedication from the generations of activists or pioneers, which motivated and cultivated the new wave of black generations against the discrimination. The emergence of new media era introduces the African American with unparalleled opportunity. Social media plays a role of a virtual stage where black people expresses their ethnic identity and social status, unlike the previous epoch with confined information flow, interaction and reciprocation between ethnic groups evolves towards refined transparency and convenience. The prevalence of racism as deemed as ingrained and inexorable in the past. However, when it boarded the express train of the time exhibiting itself in social media, public opinion was no longer constrained by politicians in their brain-washing propaganda, and flexibly bypassed the politics to observe the authentic African American groups directly and transparently with the increasement in the likelihood of interracial interaction.

\section{SOCIAL MEDIA AS NON-PLACE STRENGTHENS ETHNIC IDENTITY}

Free from spatial and temporal constraint, social media congregates ethnic groups in a specific space. While the existence of ethnic group boundaries is unneglectable, social media still fortifies the ethnic identities among ethnic groups. In reality, due to the invisible ethnic boundary in a sense of morality people from different ethnic group tend to subconsciously assemble around their members to gratify the selfidentity and ethnic identity. However, as the physical space confines the transparency of the boundary, foreign ethnic group experiences a hard time exploring cultural and spiritual core of black ethnic group, let alone interracial reciprocation and development. Consequently, social media, where everyone shares their cookies or data, functions as a public stage for potential mutual interactions between ethnic groups. Surely, the dimensions of so-called interracial communication are debated by scholars, among those popular theories, there are two theories favored by majority- essentialism and instrumentalism. Researchers from essentialism reckon that the interaction between ethnic groups concentrates on cultural and historical dimension. Although so far there is no particular research discovering and exploring the relationship between social media and essentialism, evidently the prevalence of social media establishes the comparatively most equitable and transparent platform for heterogeneous cultural collision. From the lens of ethnic interests, researchers from instrumentalism reckon the social media as battlefield in which ethnic groups strive for their diversified interests in order to maintain or expand the social influence, boosting the ethnic identity and exerting political power via social media.
For a thorough comprehension of ethnic boundary, it is indispensable to reintroduce and define "ethnic group". Referring to the definition from Max Weber "physical traits or habits or relative traits including both, or human group whose memory of colonization or migration are derived from homogenous subjective belief, which is vital to the formation of the group, while existence of objective kinship is subordinate" [6], regardless of nation state or multination state, classification of individuals is common and imperative. Racial classification exerts influence to some extent on boosting the prompt identification and interaction with directivity between different hierarchies in the mainstream society. Obviously, back to the case the African American students represented the black ethnic group whilst the post owner represented the white ethnic group. Naturally, another user in the comments section also easily categorized herself into the post owner's ethnic group and expressed her opinion regarding black ethnic group through the methodological classification above. Additionally, from the perspective of the post owner, another ethnic group seemed to have violated and contaminated the sanctity belonging to her ethnic group, which indicates that the boundaries between different ethnic groups, whether in society or on social platforms, are impenetrable.

\section{EMERGENCE OF ETHNIC BOUNDARY AND EXPRESSION OF ETHNICITY}

It is worth noting that, according to the famous Manchester School of anthropology founder Max Gluckman, who originated his inspiration from the conceptualization of maintaining boundaries, he suggested that both racism and associated ethnic issues emanate from contact between different ethnic groups. As for multi-nation state, "since human affiliates with fixed ethnic communities, as a result of genetic evolution and kinship, ethnicity is by and large a priority-established and potent social constraint. Ethnic ties possess logical and temporal precedence, coercive power and sentiment. Ethnic constraints that override other loyalties. This mighty sense of identity and solidarity from the lineage, the original identity, engenders obstacles that impede or even undermine the process of nation-building" [7]. Interactions between different ethnic groups are prone to maintain and operate distinct boundaries. The social limitations and adverse consequences of ethnic constraints are familiar to African Americans living in the United States. The Beijing News indicates that while the U.S. Labor Department reported on June 5 that the country's unemployment rate fell to 13.3 percent from 14.7 percent in April, the unemployment rate for black Americans rose to 16.8 percent in May, the highest in more than a decade, from 16.7 percent in April. By contrast, the unemployment rate for white Americans fell to 12.4 percent in May from 14.2 percent in April 
[18]. In early stage of America, when racial discrimination was more severe and drastic, there were explicit rules in terms of specific locations prohibiting black American, which largely attributed to boundary. Even in contemporary society, the boundary of ethnic groups seems to be gradually blurred with the development of the Internet, however, the phenomenon that a certain space is dominated by one ethnic group, for instance, "Black Twitter", once again substantiates that the boundary between ethnic groups is arduous to diminish. From Bryers' The Use of Twitter Hashtags in the Formation of Ad Hoc Publics. Paper presented at the European Consortium for Political Research conference pointed out that African Americans are far more likely to use Twitter (22 percent) than white Americans (16 percent). The essential rationale for this phenomenon could be concluded that "whereas in most mainstream media contexts the experiences of racialized populations are overdetermined, stereotyped, or tokenized, social media platforms such as Twitter offer sites for collectively constructing counternarratives and reimagining group identities" [8].

For ethnic boundaries, the Anthropologist from Norway mentioned in his classic study of ethnicity that "what constitutes an ethnic group depends on its relationship to other groups focalizing on boundaries, while boundaries are production of society attached with manifold significance and may change over time" [9]. As for the development of boundary forms of expression, it is essential to introduce essentialism that many anthropologists have examined and developed. Essentialism, as its name implies, is the most intuitive way to distinguish one ethnic group from others in terms of history and culture, such as the language, customs and etc. For instance, in USA, black community owns its peculiar language, academically known as African American Vernacular English or Ebonics; precisely, this language is a dialect, differing from accents in various states, it shapes its particular linguistic system even if it is labeled as representation of undereducation by mainstream society. In this sense, social media platform not only operates as the rendezvous for different ethnic groups, but also brings the indigenous culture of different ethnic groups onto the media stage. Meanwhile, the local culture of this ethnic group transforms into the so-called shared culture, and by dissemination of social media it gives rise to opportunity for reciprocal interaction between different ethnic groups. Stereotypes are always rooted in ignorance and prejudice against other cultures, which further highlights ethnic boundaries. Shared culture itself, to a certain extent, can eliminate the so-called stereotypes and ameliorate understanding together with tolerance between different cultures. American scholar Charles Keyes in favor of Essentialism conceptualized it as the "share descent" and "it's a cultural interpretation, and a native, innate trait of the ethnic group" [10].
Contrast to this theory, it is theory without individual views in ethnic groups initiating from the perspective of political power- instrumentalism. "When it comes to identity politics in Europe and the United States, it is not possible to evade that iconic era", Friedman claims that "since the mid-1970s, even earlier in the United States, political culture has commenced a comprehensive shift toward cultural identity politics related to gender, locality or ethnic identity at the level of modern politics based on general progress and development" [11]. All too familiar to any African American who underwent that suppressing era, politicians then disguised their announcement of war on crime, while effectively incarcerating black people and manipulating the media for criminalization of black people to brainwash the masses and acquire the constitutes from the major citizens. African Americans were victimized by political maneuvering, setting the tone for their subsequent incarceration in society. As defined by instrumentalism, ethnic identity is the strategic response of ethnic groups to specialized situations submissive to individual or group standards, and it is an apparatus applied in the competition of politics, economy and other social rights and interests. In the meantime, via political propaganda to indoctrinate young black descendants by generations and undermine their own ethnic identity, as anticipated the situation eventually culminate as a result of recurrence of contemporary slavery for the white class

\section{ROOT OF IMBALANCED ETHNIC IDENTITIES}

The demonstration of ethnicity by different ethnic groups is representation of the gladiatorial struggle between underprivileged groups and dominating groups, moreover, it represents the contention for individual or ethnic group in terms of interests or resources. For a multi-ethnic country, it is a tremendous mission to coordinate the distribution of social resources among ethnic groups. However, it will inevitably lead to imbalance between ethnic groups, which can be summarized to a large extent in two aspects: economy and culture. For the black ethnic groups in the United States, due to the dependency on capitalist system, the racial bourgeoisie suffers from decadence while the whole hierarchy experiences a low level of radical revolutionary spirit, which gives rise to severer marginalization of the black group in the United States. Fortunately, the aforementioned use of Twitter as a voice for resistance has somewhat lowered the bar for fighting racism. One of the most widely circulated memes of the "Michael Brown" incident was the hashtag \#HandsUpDontShoot created by a Student at Harvard University. By participating in the event, students "sought to call attention to the arbitrary nature of racialized policing, the vulnerability of black bodies, and the problematic ways in which blackness is 
perceived as a constant threat" [12]. However, with the advancement and evolution of the degree of modernization in the world, "although the inclusion of a wider range of groups into the central domain, but at the same time paradoxically produced the potential for these groups to become alienated from the central political and social system" [13].

For African Americans, who had been regarded as a disadvantaged group or minority group, the historical gear brought them closer to the main group step by step, but only intensified the dependence and possibility of conflict between ethnic groups. The cognitive dissonance brought by these inequalities and challenges to ethnic groups gradually accumulated into dissatisfaction, resentment and other negative emotions towards the system and the country. The reason for this so-called inequality is psychological: a sense of relative deprivation. The classical theory of Relative deprivation (RDT) believes that "individuals evaluate their status and situation mainly by comparing with others, members of disadvantaged groups often experience the feeling of being deprived of their basic rights, which not only deprives them of many opportunities in real life, but also jeopardizes their psychological development" [19]. What is easily confused is that the relationship between social comparison and relative deprivation is not the similarity or juxtaposition of conventional understanding, but "social comparison refers to the process in which an individual evaluates his own ability, behavioral level and behavioral results compared with those with similar life situations" [15]. The core of relative deprivation theory lies in "the process of social comparison" [16]. For the relatively deprived group, "downward comparison tends to produce relative satisfaction or satisfaction, while upward comparison may produce two distinct feelings: one is progress with upward struggle whilst the other is relative deprivation or loss" [17].

According to a large number of studies, there is a "significant positive correlation" [14] between group relative deprivation and nationalistic attitudes. It is easy to understand in one way why racism on social media is so difficult to solve in a significant way, because the discriminated greatly deepens the racial divide. As the social status of African Americans could not be guaranteed, the sense of relative deprivation drove them to form a strong ethnic identity in order to express their dissatisfaction, and they began to retaliate against other ethnic groups by means of fighting for equal social status through political means, including but not limited to violent demonstrations.

Once again, when relating to the racist post by FSU students, it becomes clear how bad and influential it was. As a vulnerable group in the school, the black ethnic group experienced a more serious sense of relative deprivation after the incident. For the sustainability of ethnic groups in the school, the incident is likely to escalate between the two ethnic groups and eventually contribute to unnecessary conflict. However, such warmongers play into the hands of the nationalists who are in a dominant position. The mission of purifying the nation and saving the country has been engraved in their genes, and they are always ready to devote themselves to the undertaking of nationalism.

\section{POTENTIAL SOLUTIONS TO IMBALANCED ETHNIC IDENTITY}

When the spotlight converges back to social media, discussing the viable solutions to racism is baffled by any means. Constitutional provisions, for example, freedom of speech, which are supposed to protect and defend basic human rights, have been distorted as sheltering the prevalence of racism. Furthermore, different media platforms confront numerous obstacles to implement appropriate and uniform censorship on the posts. In fact, the so-called social media represents as a virtual space reflecting the miniature of the physical society. Therefore, instead of concentrating on social media, it would be valuable to expand the dimension tackling the issues in society, which indirectly sustains the positive speech atmosphere on social platforms. In addition to eliminating the imbalanced economic development and the relative deprivation psychology in culture mentioned above, it is necessary "to construct the unitary political consciousness, namely the national consciousness, on the basis of recognizing the dual identity and revering the cultural diversity" [20]. "The purpose of modern state governance" emphasized by Foucault is "to enable citizens of the state to enjoy the benefits provided by the state and believe that their government can guarantee them" [21], That is, to adjust the interaction between various ethnic groups and allocate social resources reasonably.

Among them, the dual identity is reflected in the "identification of ethnic group (ethnic culture) and national identity (political identity)" [21]. For ethnic groups, collective culture, tradition and language energize ethnic identity towards a more dynamic way. According to Habermas' new sense of belonging theory, this new sense of belonging is not based on the uniformity of people's ethnic lineage in the community, instead through the legal construction of citizens' individual rights and freedoms, to create citizens' recognition of the national unity. That is to say, in addition to respecting ethnic culture, not suppressing and restricting the development of subcultures, and diminishing disparities and oppositions brought by cultural differences, additionally, attempting and cultivating the development of national comprehensive culture. This does not advocate that the subculture is compulsorily integrated into the mainstream culture. The premise of promising development of race relations 
in the United States is due to the abandonment of the assimilation policy. In order to promote the enhancement of national identity consciousness, apart from the recognition of the state by ethnic groups, the state should "gratify the requirements of the ethnic group, adapt to the values of the ethnic group, adjust the national system, implement cultural integration schemes, upgrade the institutions and ways of interest expression, and strengthen the sense of identity" [21].

To promote the common development of the national culture does not contradict the diversity of culture, on the contrary can be enhance national cohesion to realize stable multi-ethnic society environment essential factor Moment for unitary political direction need to actively cooperate with various nationalities and the principle of implementation to maximize the guarantee of national harmony and promote national development and progress. At the same time, nation can advocate the heterogenous ethnic identity by initiating the identification of various ethnic groups in the form of classification of the population. While to avoid the disadvantaged groups protected by a strong group annexation of affection, self-development thrives for vulnerable groups, which ensures the interests of the ethnic minorities to eliminate inequal mentality then to build a positive social atmosphere. Vulnerable groups with self-management nature largely attributes to social media. Through the social platform, a refined community system establishes, while a more comprehensive and systematic benign ethnic interaction is initiated eradicating the phenomenon such as disintegration, with the interests of the ethnic guaranteed at the same time, the development of the ethnic group will manifest towards naturally sustainable tendency.

Thanks to the fluidity of social media, the deprived ethnic groups can also refer to the triumph of the dominating groups and apply to their own status. With the development of the disadvantaged groups, Cannikin Law begins to invalidate, and a stronger and united multi-ethnic community will take its place.

\section{CONCLUSION}

This article demonstrates and exemplifies the discussion with a classic and symbolic case study on racial discrimination against African American occurring in social media. Encompassing ethnic identity where the inception is initiated from supplementary discussion on development of black ethnic identity under structural oppression in history, continuing on the efforts social media accomplished in boosting ethnic identity, in depth maintaining the flow in discussion regarding forms and expressions of ethnic boundary and ethnicity, analyzing the phenomenon of marginalization and rationale in terms of black community as underprivileged group in American society, culminating the discussion by proposing the dual identity to terminate the racial discrimination radically in society. As the title indicates, this article attempts to discuss and eventually put an end to racism against African American among social media platforms. Recently, since human rights campaigns for black community increased, it is obvious that people from various ethnic groups participated in the movement together with black community. It is believed that in this new media era social media plays certain role in gathering every American as an integral unity towards a promising future.

\section{REFERENCES}

[1] Adriennea, C. (Ed.). (2013, September 8). Racist Social Media Post Targets FSU Students. Orlando Sentinel.

https://www.orlandosentinel.com/features/goneviral/os-fsu-students-racist-vine-post-090813post.html

[2] Tao, J.J. Introduction to identity[J]. Foreign Literature, 2004(02):37-44.

[3] Hinton, Elizabeth and Cook, DeAnza, (2021). The Mass Criminalization of Black Americans: A historical overview.

Annual Review of Criminology, Vol. 4, pp. 261-286. http://dx.doi.org/10.1146/annurev-criminol060520-033306

[4] Blackmon DA. 2008. Slavery by Another Name: The Re-Enslavement of Black Americans from the Civil War to World War II. New York: Anchor Books

[5] Balto S. 2019. Occupied Territory: Policing Black Chicago from Red Summer to Black Power. Chapel Hill, NC: UNC Press

[6] Weber, Max, 1864-1920. (1954). Max Weber on law in economy and society. Cambridge: Harvard University Press

[7] Zhang, Y.G. Ethnic group identity and nation identity: How is concord possible [J]. Journal of Capital Normal University (Social Sciences Edition),2008(05):150-153.

[8] Bonilla, Y. and Rosa, J. (2015), \#Ferguson: Digital protest, hashtag ethnography, and the racial politics of social media in the United States. American Ethnologist, $\quad 42$ : 17. https://doi.org/10.1111/amet.12112

[9] Fredrik Barth, "Introduction" in Fredrik Barth (ed.), Ethnic Group and Boundaries: The Social Organization of Culture Difference. London: George Allen and Unwin (1969): 9-38. 
[10] Charles F. Keyes, "The dialectics of ethnic change" in Charles F. Keyes (ed.), Ethnic Change. Seattle: University of Washington Press (1981): 8-30.

[11] Jonathan Friedman, Cultural Identity and Global Process (London :S age Publications, 1994), p .234.

[12] Muhammad, Khalil G. (2010). The Condemnation of Blackness: Race, Crime, and the Making of Modern Urban America. Cambridge, MA: Harvard University Press.

[13] Eisenstadt, S. N. (2004). Social Evolution and Modernity: Some Observations on Parsons's Comparative and Evolutionary Analysis: Parsons's Analysis from the Perspective of Multiple Modernities. The American Sociologist, 35(4), 524. http://www.jstor.org/stable/27700401

[14] Guimond, S., \& Dubé-Simard, L. (1983). Relative deprivation theory and the Quebec nationalist movement: The cognition-emotion distinction and the personal-group deprivation issue. Journal of Personality and Social Psychology, 44(3), 526-535.

[15] Lin, C.D., Yang, Z.L., \& Huang, X.T. (2004). The comprehensive dictionary of psychology. Shanghai: Shanghai Education Press.

[16] Zhang, S. W., Wang, E. P., \& Chen, Y. W. (2011). Relative deprivation based on occupation: An effective predictor of Chinese life satisfaction. Asian Journal of Social Psychology, 14(2), 148158.

[17] Guo, X.H. (2001). The Positive research on the relative deprivation of urban population. Journal of Renmin University of China, (3), 71-78.

[18] Liu, M.J. (2020, June 20). Ten figures to expose the systematic racism in America. Beijing News. https://www.bjnews.com.cn/detail/1592649897153 34.html

[19] Mummendey, A., Kessler, T., Klink, A., \& Mielke, R. (1999). Strategies to cope with negative social identity: Predictions by social identity theory and relative deprivation theory. Journal of Personality and Social Psychology, 76, 229-249.

[20] Fan, K. Brief introduction to ethnic identity and heterogenous ethnic. [J]. The Journal of Jiangsu Administration Institute, 2015(04):52-58.

[21] Michel Foucault, "Governmenentality" in James Faubion (ed.), The Essential Works of Foucault, 1954-1984, Vol.3, Power. New York: New Press (2000): 201-222 